\title{
Anthropometric and Hemodynamic Profiles of Athletes and Their Relevance to Performance in the Mount Cameroon Race of Hope
}

\author{
Authors' Affiliation: \\ 1. Department of Animal \\ Physiology, Faculty of Science, \\ University of Buea, Cameroon \\ 2. Faculty of Health Sciences, \\ University of Buea, Cameroon \\ 3. Regional Hospital, Annex Buea, \\ Cameroon \\ * Corresponding Author; \\ Address: University of Buea, \\ Cameroon. P.O. Box 12, Pouma, \\ Cameroon \\ E-mail: tofocal@gmail.com \\ Received: Nov 08, 2011 \\ Accepted: Jan 11, 2012
}

Key Words: Anthropometry; Blood Pressure; Mountaineering; Altitude; Performance; Cameroon

\author{
Martin A. Salah ${ }^{1,2}$, PhD; Vincent S. Verla ${ }^{2,3}$, MD; Calvin Tonga ${ }^{{ }^{*}}$, MSc
}

\begin{abstract}
Purpose: Many factors influence athletes' performance including anthropometric, physiological and environmental parameters. High altitude is characterized by adverse environmental conditions that are not found at sea level. We investigated the influence of some anthropometric and physiological factors on performance in the context of the Mount Cameroon Race of Hope.
\end{abstract}

Methods: Age, height, weight, blood pressure, heart rate and breathing rate of 83 finisher athletes of both genders were collected during medical checkup, and race time was recorded at the arrival line. Measured and calculated data association with performance was assessed.

Results: The race time was significantly influenced by the area of training $(p=0.0022)$, and gender $(p=0.0036)$ of athletes; BMI showed significant association with race time in the overall athletes' population; this was confirmed in male $(r=0.565 ; p=0.034)$ but not in female athletes $(r=0.749 ; p=$ 0.058). Weight class showed significant association to performance, the lighter athletes performing better than the heavier $(p<0.00001)$. None of the investigated physiological parameters showed association to the race time.

Conclusions: We hypothesized that high altitude training and body size are significantly influential on athletes' performance in the Mount Cameroon race of hope and similar mountain races.

Asian Journal of Sports Medicine, Volume 3 (Number 2), June 2012, Pages: 99-104

\section{INTRODUCTION}

A multitude of factors affect physical performance. Beside biological factors such as age, sex, height, weight and body composition, a variety of external influences contribute to observed performance, including nutrition, psychological and training status, fatigue, drugs, and environmental factors ${ }^{[1,2]}$. Like anthropometric parameters, several physiological factors show an association with endurance performance. Some of these, such as lactate threshold, oxygen uptake, running economy, hemoglobin concentration, energetic metabolism and fiber types proportion in muscle have been shown to impact athletes' performances in endurance and extraendurance competitions ${ }^{[3,4,5]}$.
The effects of altitude on physical performance are extensively discussed and divisive for specialists of environmental considerations in sport ${ }^{[6]}$. Increase in altitude, results in more intense solar radiation and reduction of barometric pressure, ambient temperature, relative humidity, air density and partial pressure of all gases including oxygen. Athletes in this context have to face many adverse environmental conditions, the most important being hypoxia with its incidence on physical performance. To counter these problems, the body generates immediate and complex compensations in respiration, metabolism, and hemodynamic regulations for the redistribution of blood flow to vital organs and maintenance of systemic oxygenation which is critical for survival ${ }^{[7,8]}$. 
The effects of both physiological and anthropometric factors vary, depending on the intensity, duration, mode and some other peculiarities of physical exercises. Data available on the impact of these factors on athletes have mostly been obtained at sea level. Few studies have been carried out for high endurance in the context of high mountain racing and they mostly aimed at assessing physiological response. As the mount Cameroon Race of Hope is concerned, only one study was found in literature and aimed to assess the effects of sickle cell traits on athletes' performance ${ }^{[9]}$.

The Race of Hope is a grueling footrace that gives a good opportunity for assessing the impact of some anthropological and physiological parameters on athletes' performance in the context of high altitude competition. However, no scientific data is presented in international literature.

\section{METHODS AND SUBJECTS}

The present work is a transversal study based on data collected from athletes who participated in the 2011 Race of Hope. The study was approved by the local Institutional Review Board. Oral informed consent was received from all participants after verbal explanation of the experimental design.

\section{Subjects:}

In February 2011, 124 athletes (110 males and 14 females) finished the race to the summit and back in the official time. Data from 73 male and 12 female volunteer finisher athletes collected during medical fitness control were used for the purpose of this study, as athletes who had incomplete data, who were disqualified at the medical checkup or in the course of the race were excluded. The athletes were from seven regions of Cameroon, situated at varied altitudes (Table 1).

\section{The area and the race:}

Mount Cameroon is a live volcano situated at Longitude $9^{\circ} 170^{\prime}$ East and Latitude $4^{\circ} 203^{\prime}$ North, part of the $1600 \mathrm{~km}$ long chain of Cenozoic volcanic and sub-volcanic complexes that extends from the Gulf of Guinea to the interior of the African continent, known as the Cameroon Volcanic Line ${ }^{[10]}$.

The town of Buea in the South-West region of Cameroon hosts the Race of Hope, an annual sport event that takes place each month of February in the course of the main dry season. The main race covers a marathon distance of $42,000 \mathrm{~m}$, ascending mount Cameroon, to its $4,090 \mathrm{~m}$ summit and back to the Molyko stadium over a 6,096 m vertical feet round-trip ${ }^{[11]}$. The race takes athletes from different origins through various climactic zones such as rainforest, savannah, up to the freezing summit. They have to face very difficult conditions such as temperature fluctuation, mountain malaise and injuries due to loose volcanic stones, exposing them to harder conditions than those admitted by international norms and thus, to adverse reactions such as injuries and Acute High Altitude Diseases ${ }^{[12,13]}$. The 2011 race took place on the $26 / 02 / 2011$ and saw the participation of athletes from different origins within the country and from abroad. The race was launched at 7.30 am and the last official finisher was recorded at $4.30 \mathrm{pm}$.

Table 1: Performances of athletes from various training altitudes

\begin{tabular}{lcccrc}
$\begin{array}{c}\text { Training } \\
\text { regions }\end{array}$ & $\begin{array}{c}\text { Mean altitudes of } \\
\text { regions (m) }\end{array}$ & $\begin{array}{c}\text { Number of } \\
\text { athletes }\end{array}$ & \multicolumn{2}{c}{ Rean (SD) } & Range \\
\hline Littoral & 22 & 8 & $25251(2440)$ & $19816-27734$ \\
Adamaoua & 271 & 1 & $23512 \quad(0)$ & -- \\
East & 717 & 2 & $27048(970)$ & $26362-27734$ \\
Center & 855 & 7 & $21493(3505)$ & $17842-26734$ \\
South-West & 1000 & 20 & $21872(3060)$ & $16967-26874$ \\
West & 1390 & 9 & $21678(3183)$ & $17072-24659$ \\
North-West & 1615 & 37 & $21455(3280)$ & $16149-28933$
\end{tabular}

SD: Standard Deviation 
All athletes had their anthropological and physiological measurements recorded during the medical fitness control visit by the appointed health crew based in the Regional Hospital annex in Buea, on the $14^{\text {th }}$ and $15^{\text {th }}$ Feb 2011. Information was also recorded on the region of training of athletes.

\section{Measurements and calculations:}

Anthropometric characteristics (height and weight) were measured using a SECA $^{\circledR} 755$ dial column mechanical scale with included $\mathrm{SECA}^{\circledR} 220$ height rod; BMI was calculated and athletes were classified as underweight $(\mathrm{BMI}<18)$, normal $(18 \leq \mathrm{BMI}<25)$ and overweight $(\mathrm{BMI} \geq 25)$ according to the WHO classification $^{[14]}$

The resting Systolic Blood Pressure (SBP) and Diastolic Blood Pressure (DBP) were measured on the right arm of each participant using cuffs of appropriate size and calibrated Spengler ${ }^{\circledR}$ VAQUEZ-LAUBRY, integrated aneroid sphygmomanometer and a stethoscope. Optimal blood pressure was defined as a $\mathrm{SBP}<120 \mathrm{mmHg}$ and $\mathrm{DBP}<80 \mathrm{mmHg}$. Pre-hypertension was defined at a SBP of 120 to $139 \mathrm{mmHg}$ and/or DBP of 80 to $89 \mathrm{mmHg}$, and hypertension was diagnosed at a $\mathrm{SBP} \geq 140 \mathrm{mmHg}$ and/DBP $\geq 90 \mathrm{mmHg}$, according to international guidelines ${ }^{[15]}$. Mean arterial pressure (MAP) was calculated as $(\mathrm{SBP}+2 \times \mathrm{DBP}) / 3$ and the average $\mathrm{BP}$ (ABP) as SBP - DBP. Pulse and breathing rate were assessed, counting the beats of the radial artery and the movements of the chest respectively, for
1 minute using a chronograph. The measurements were taken after subjects were in resting position in a calm, quiet environment for at least 10 minutes.

\section{Statistical analysis:}

The data are expressed as means \pm standard deviation. Anthropometric and physiological parameters were correlated with race times. Statistical analysis was performed with the Statistica ${ }^{\mathrm{TM}} 7.0$ package. They were used in linear regression analysis to identify the performance relevant anthropometric and physiological parameters. Directly measured anthropometric and physiological data (body mass, height, resting Systolic $\mathrm{BP}$, resting Diastolic BP and resting Heart Rate) and calculated data (BMI, Differential Blood Pressure, Mean Blood Pressure), were compared using the one tail ANOVA model with the F-test. The significance level was established at $P$-value $<0.05$.

\section{RESULTS}

Anthropometric and physiological characteristics of male and female athletes are presented in Table 2. Underweight athletes were $3.6 \%$, athletes in the normal range $83.1 \%$ and overweight athletes $13.2 \%$ of the overall athletes' population. Anthropometric parameters showed statistically significant difference

Table 2: Anthropometric and physiological parameters of athletes

\begin{tabular}{lccccccc} 
& \multicolumn{2}{c}{ General (n=83) } & \multicolumn{2}{c}{ Males (n=71) } & \multicolumn{2}{c}{ Females (n=12) } \\
Parameter & Mean (SD) & Range & Mean (SD) & Range & Mean (SD) & Range & value \\
\hline Age (Years) & $28.6(6.08)$ & $18-44$ & $28.9(5.95)$ & $18-44$ & $26.83(6.81)$ & $19-38$ & 0.3 \\
Height (cm) & $168.57(6.60)$ & $150-191$ & $169.85(5.97)$ & $159-191$ & $161(4.99)$ & $150-167$ & $<0.001$ \\
Weight (Kg) & $64.19(7.43)$ & $46-85$ & $64.79(7.41)$ & $46-85$ & $60.63(6.79)$ & $51-72$ & 0.07 \\
Systolic Blood Pressure (mmHg) & $130.41(12.63)$ & $102-167$ & $132.49(11.91)$ & $102-167$ & $118.08(9.63)$ & $103-130$ & $<0.001$ \\
Diastolic Blood Pressure (mmHg) & $72.18(9.63)$ & $50-105$ & $72.65(10.01)$ & $50-105$ & $69.42(6.65)$ & $56-80$ & 0.3 \\
Average Blood Pressure (mmHg) & $58.23(13.33)$ & $27-97$ & $59.85(13.16)$ & $27-97$ & $48.67(10.27)$ & $32-64$ & 0.006 \\
Mean Arterial Pressure (mmHg) & $91.59(8.69)$ & $71.67-115.67$ & $92.6(8.69)$ & $71.67-115.67$ & $85.64(6.08)$ & $76.67-94.33$ & 0.009 \\
Heart rate (Pls/min) & $66.61(10.69)$ & $42-93$ & $65.81(10.33)$ & $42-88$ & $71.25(12.02)$ & $50-93$ & 0.1 \\
Breathing rate (Mvt/min) & $16.77(2.43)$ & $11-23$ & $16.41(2.26)$ & $11-20$ & $19.09(2.26)$ & $15-23$ & 0.01 \\
Body Mass Index (Kg.m-2) & $22.60(2.40)$ & $15.02-28.67$ & $22.46(2.29)$ & $15.02-28.07$ & $23.45(2.97)$ & $18.73-28.67$ & 0.2 \\
Race time (In seconds) & $22032(3279)$ & $11585-28933$ & $21610(3208)$ & $11585-16149$ & $24531(2588)$ & $20034-28933$ & 0.003 \\
\multicolumn{1}{|c|}{ SD: Standard Deviation } & & & & & & &
\end{tabular}


between male and female athletes for the body height, but not for the BMI and body weight. Significant differences were observed between male and female athletes for Systolic BP, MAP and ABP. However, no significant gender difference in physiological parameters was found for heart rate and DBP.

The prevalence of optimal blood pressure, prehypertension and hypertension in athletes was $13.25 \%$, $67.47 \%$ and $19.28 \%$ respectively, with the systolic blood pressure and $73.49 \%, 21.69 \%$ and $04.82 \%$ respectively with diastolic blood pressure. Hypertension with both parameters was only found in male athletes.

Concerning athletes' performances, the race time was significantly influenced by the gender of athletes $\left(F_{1},{ }_{81}=8.938, \quad P=0.004\right)$, their region of training $\left(F_{4,81}=4.577, P=0.002\right)$, and in males only, the height $(\mathrm{r}=-0.512 ; P=0.02)$ and BMI $(\mathrm{r}=0.565 ; P=0.003)$ (Fig. $1,2)$. A significant race time difference was found between underweight, normal and overweight athletes (race time $18594 \mathrm{~s}, 21802 \mathrm{~s}$ and $24415 \mathrm{~s}$ respectively; $\left.F_{2,80}=62.657, P<0.001\right)$.

No influence of height or BMI on performance was observed in female athletes $(\mathrm{r}=0.079, P=0.06 ; \mathrm{r}=0.749$, $P=0.06)$ and no physiological parameter either measured or calculated showed significant influence on athletes' performance.

\section{DISCUSSION}

The present study shows a significant effect of BMI on the performance of male athletes. As is the case with long distance runners, BMI influenced the performance of Mount Cameroon athletes, yielding a positive correlation with the race time, the speed being higher in athletes from the underweight to the overweight. This finding is in accordance with the general pattern in runners ${ }^{[16]}$. In fact, chronic exposure to reduced partial pressure of oxygen as it is the case at high altitude, decreases arterial oxygen saturation, provoking shifts in substrate metabolism ${ }^{[17]}$. This increases the difficulty for the body to use oxidative phosphorylation to produce the energy needed for endurance exercise; the glycolytic pathway is therefore favored rather than other catabolic pathways, including fat catabolism for energy production, because it has the lowest oxygen cost. A greater ability in fats use for energy production by females may explain the difference observed with males concerning the influence of BMI on performance. The sex specificity of this shift has already been reported ${ }^{[5,18]}$. However, the reduced sample size does not allow for any objective conclusion.

Nevertheless, our finding contrast with that of triathletes in whom no influence of BMI was found on

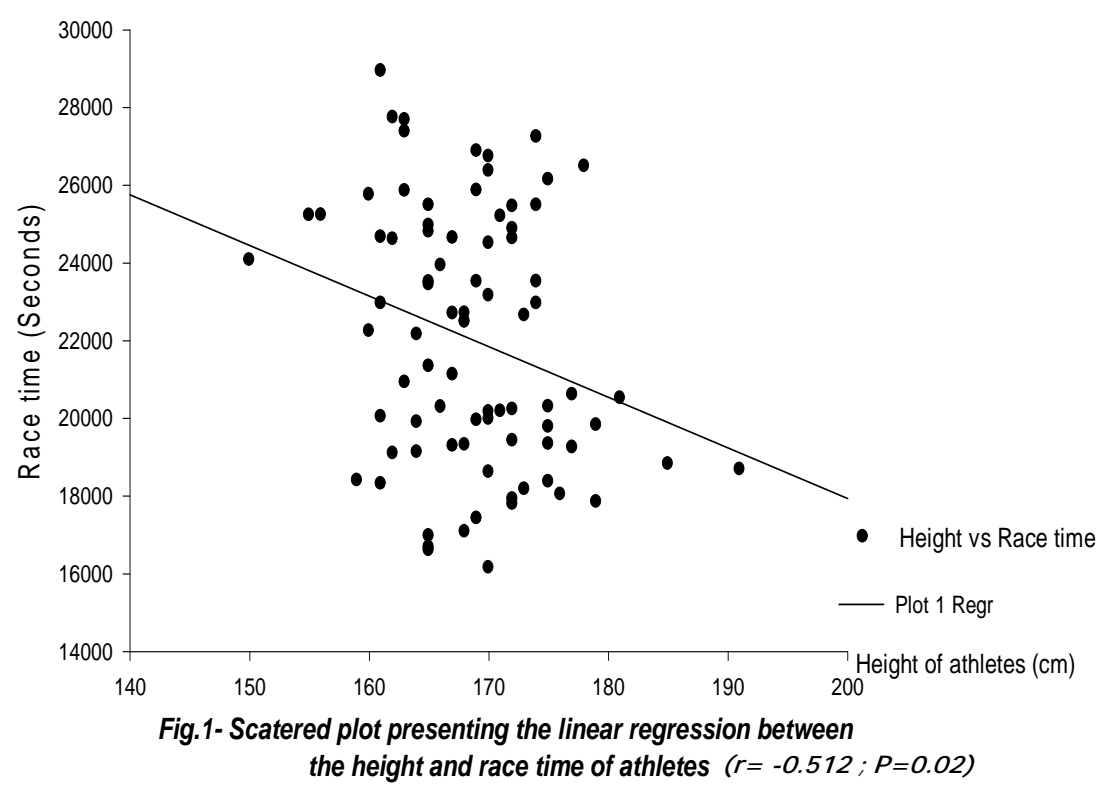

Vol 3 No 2, Jun 2012 


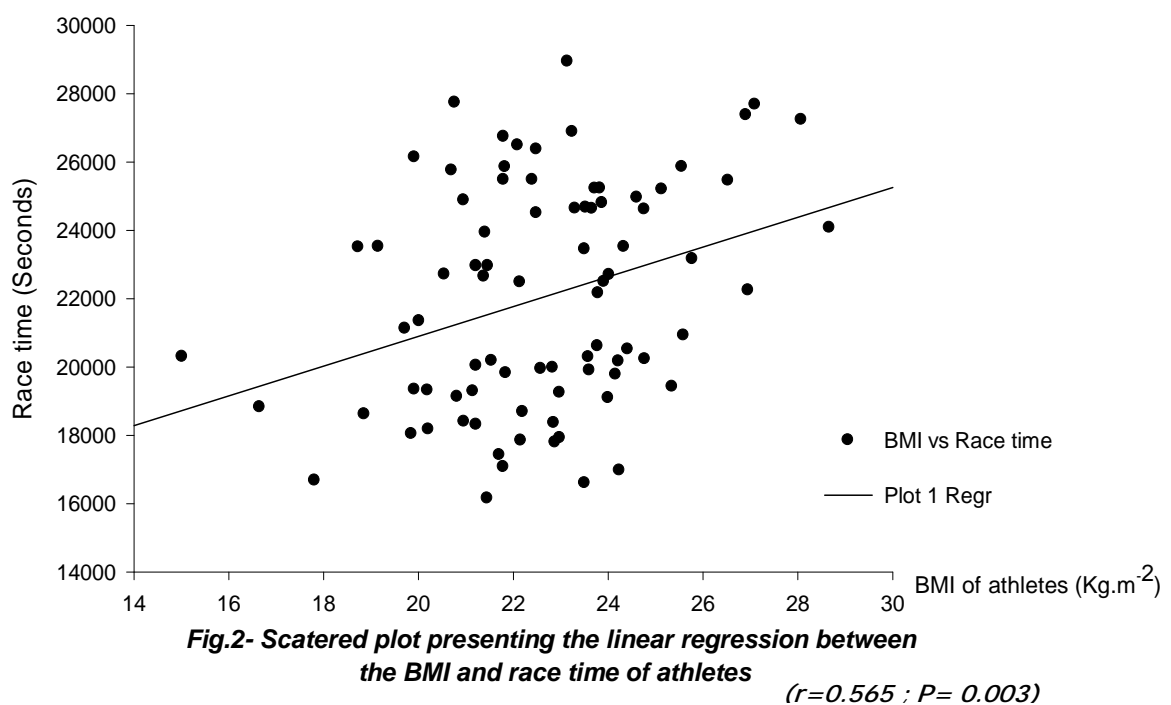

the performance ${ }^{[19]}$; this might be due to the varied set of exercises (swimming and cycling, added to running), the longer duration of the race with recovery periods and differences in environmental conditions.

Training area was highly influential on the performance of athletes. The results showed better performance for athletes from low to high altitude training sites. This is in accordance with previous investigations which showed that natives of high altitude areas or those athletes training at high altitude perform better both in low and high altitude. This has lead athletes to implement the "live high, train high" preparation system, and can be explained by the favorable genetic background in natives and adaptation to the high altitude environment; these enhance exercise capacity and tolerance both at sea level and high altitude ${ }^{[2,20,21]}$.

Men had better $s$ than women; this owes to their higher muscle mass and their higher maximal oxygen consumption $\left(\mathrm{Vo}_{2} \mathrm{Max}\right)$ that make them more powerful in efforts ${ }^{[22]}$.

None of the assessed physiological parameters had a significant influence on athletes' performance. This could be explained by the fact that aptitude to race is mostly tributary to the compliance of the body system so that acute physiological adjustments to maintain body homeostasis are produced, which are not directly related to resting body functions parameters.
The results of this investigation could be bias as no data was collected concerning the training status of participants. However, this information database is of great interest, and to the best of our knowledge, it is the first time that data are collected for scientific investigations in the course of the Mount Cameroon Race of Hope which has the peculiarity of acutely taking the athletes up an down the mountain, in the shortest length of time. Furthermore, data on high altitude mountain competition are not commonly found in literature.

\section{CONCLUSION}

The essential findings in this study are that altitude of training, height and BMI were significantly influential on athlete's performance in high mountain competition whereas other anthropometric parameters as weight, age, and physiological data as resting blood pressure, heart rate and breathing rate do not influence performance. These results could be useful for athletes' preparation for the competition as success might depend on the acclimatization to high altitude environment, body size and thus, on diet. 


\section{ACKNOWLEDGMENTS}

The authors would like to express their gratitude to the National Federation of Athletism of Cameroon, the Regional Delegation of Public Health for the south-
West Region for the administrative and ethical clearances and all the athletes who accepted to participate in this study.

Conflict of interests: None

\section{REFERENCES}

1. Tanaka H, Seals DR. Endurance exercise performance in Masters athletes: age-associated changes and underlying physiological. $J$ Physiol 2008;586:55-63.

2. MacInnis MJ, Koehle MS, Rupert JL. Evidence for a genetic basis for altitude illness: 2010 update. High Alt Med Biol 2010;11:349-68.

3. Kravitz L, Dalleck LC. Physiological Factors Limiting Endurance Exercise Capacity. In: IDEA Health \& Fitness Association. Advanced sports conditioning for enhanced performance. IDEA Resource Series 2002; Pp:21-7.

4. Hoppeler H, Vogt M. Muscle tissue adaptations to hypoxia. J Exp Biol 2001;204:3133-9.

5. Martin DS, Levett DZH, Grocott MPW, Montgomery HE. Variation in human performance in the hypoxic mountain environment. Exp Physiol 2009;95:463-70.

6. Wyatt F. Physiological responses to altitude. In: American Society of Exercise Physiology. The ASEP's study guide. The center of Exercise Physiology-Online 2004. Retrieved from http://www.exercisephysiologists.com/Altitude/index.html. Access date: 25/05/2011.

7. Yasuma F, Hayano JI. Impact of acute hypoxia on heart rate and blood pressure variability in conscious dogs. Am J Physiol Heart Circ Physiol 2000;279:H2344-9.

8. West JB. The Physiologic Basis of High-Altitude Diseases. Ann Int Med 2004;141:789-800.

9. Thiriet P, Le Hesran JY, Wouassi D, et al. Sickle cell trait performance in a prolonged race at high altitude. Med Sci Sports Exerc 1994;26:914-8.

10. Tsafack JPF, Wandji P, Bardintzeff JM, et al. The Mount Cameroon stratovolcano (Cameroon Volcanic Line, Central Africa): Petrology, geochemistry, isotope and age data. Geochemistry, Mineralogy and Petrology-Sofia 2009;47:65-78.

11. Awah ET. Soil Map of Mount Cameroon Project area. Explanatory report. Mount Cameroon Project, Buea-Cameroon. 1995.

12. Hackett PH, Roach RC. High-altitude illness. N Engl J Med 2001;345:107-14.

13. Yusheng R, Zhongming F, Weimin S, et al. Incidence of high altitude illnesses among unacclimatized persons who acutely ascended to Tibet. High Alt Med Biol 2010;11:39-42.

14. WHO, 2006. Global database on body mass index; BMI classification. Available at http://apps.who.int/bmi/index.jsp? introPage=intro_3.html. Access date: Mar 27, 2010.

15. Chobanian AV, Bakris GL, Black HR, et al. Seventh report of the joint national committee on prevention, detection, evaluation, and treatment of high blood pressure. Hypertension 2003;42:1206-52.

16. Knechtle B, Knechtle P, Rosemann T, Lepers R. Is Body Fat a Predictor of Race Time in Female Long-Distance Inline Skaters? Asian J Sports Med 2010;1:131-6.

17. Benso A, Broglio F, Aimaretti G, et al. Endocrine and metabolic responses to extreme altitude and physical exercise in climbers. Eur J Endocrinol 2007; 157:733-40.

18. Tarnopolsky MA, Zawada C, Richmond LB, et al. Gender differences in carbohydrate loading are related to energy intake. J Applied Physiol 2001;91:225-30.

19. Knechtle B, Duff B. Cycling and running performance, not anthropometric factors, are associated with race performance in a triple iron triathlon. Res Sports Med 2007;15:257-69.

20. Schoene RB. Illnesses at high altitude. Chest 2008;134:402-16.

21. Chapman RF, Stickford JL, Levine BD. Altitude training considerations for the winter sport athlete. Exp Physiol 2010;95:411-21.

22. Froberg K, Pedersen PK. Sex differences in endurance capacity and metabolic response to prolonged, heavy exercise. Eur $J$ Applied Physiol 1984;52:446-50. 